\title{
Oral labetalol in the management of stable angina pectoris in normotensive patients
}

\author{
JAMES W UPWARD, FAWAZ AKHRAS, GRAHAM JACKSON \\ From the Department of Cardiology, King's College Hospital, and Lewisham Hospital, London
}

SUMMARY The efficacy of labetalol, an alpha and beta receptor antagonist, was evaluated in 12 normotensive patients with stable angina pectoris in a single blind dose ranging study. After a two week period of placebo treatment, labetalol was given in doses of $100,150,200$, and $300 \mathrm{mg}$ twice daily, each for two weeks. Frequency of angina attacks decreased from 9.4 (SEM 2.3)/week in the control period to $7 \cdot 3(2 \cdot 8), 5 \cdot 2(2.6), 3.8(1 \cdot 8)$, and $3.3(1.9) /$ week in the four successive treatment periods. In the same periods the number of glyceryl trinitrate tablets consumed decreased from $7 \cdot 0$ (2.6)/week to 5.8 (3.3), 3.9 (2.9), $2.7(1.8)$, and 2.6 (2.1)/week. Maximal symptom limited treadmill exercise tests were performed three and 12 hours after dosage at each dose. Exercise tolerance (expressed as seconds of the Bruce protocol) increased from 266 (44) with placebo to 306 (44), 369 (50), 396 (48), and 413 (51) in the four treatment periods. This improvement was accompanied by a significant blunting of the heart rate and blood presssure responses to exercise. Trough point exercise tolerance did not differ significantly from that at three hours after dosage.

Thus labetalol is effective as an antianginal agent at doses of 150-300 mg twice daily and is well tolerated by the normotensive patient with angina.

The value of beta receptor antagonists in the management of patients with stable angina pectoris is well established. ${ }^{2}$ The benefits of beta blockade are, however, achieved at the expense of a decrease in cardiac output and an increase in peripheral vascular resistance. ${ }^{3}$ These haemodynamic effects may be important in the aetiology of the not infrequent side effects of beta blockade: cold hands and feet and fatigue. Labetalol is an agent which possesses both alpha and beta adrenoceptor antagonist properties. ${ }^{4}$ Short term studies have shown a reduction in peripheral vascular resistance after its intravenous administration ${ }^{35}$ and, compared with propranolol, less impairment of left ventricular haemodynamic performance. ${ }^{3}$ In addition, in contrast to propranolol, labetalol produces a reduction in coronary vascular resistance. ${ }^{5}$

Labetalol's main role has been in the treatment of hypertension, ${ }^{6-8}$ and in a preliminary report of labetalol treatment in patients with both hypertension

Requests for reprints to Dr G Jackson, Department of Cardiology, King's College Hospital, London SE5 9RS.

Accepted for publication 11 September 1984 and angina amelioration of anginal symptoms has been described. ${ }^{9}$

The object of this study was to assess the effects of labetalol in normotensive patients with stable angina pectoris, with reference to the control of anginal symptoms and effect on exercise tolerance.

\section{Patients and methods}

Thirteen patients (10 men and three women, mean age 59 (range 41-66) years) participated in the study. All had had clinically stable exercise induced angina pectoris for three months or longer. Table 1 summarises the patients' details. No patient had valvar heart disease, cardiac failure, obstructive airways disease, hypertension (resting diastolic blood pressure $>100$ $\mathrm{mm} \mathrm{Hg}$ ), diabetes, or renal or thyroid disease. All patients were limited on treadmill exercise testing by angina pectoris accompanied by horizontal or downsloping depression of the ST segment of $\geqslant 1.0 \mathrm{~mm}$, persisting to $80 \mathrm{~ms}$ beyond the $\mathrm{J}$ point. Eleven patients had angiographically confirmed coronary disease, defined as $>70 \%$ stenosis of at least one major vessel. The remaining two patients, who declined angiography, had typical angina and ST depression of 
Table 1 Details of patients

\begin{tabular}{llll}
\hline Case No & Age (yr)/sex & Exercise limited by & Coronary arteriogram findings \\
\hline 1 & $58 / \mathrm{M}$ & Angina & 3 Vessel disease \\
2 & $51 / \mathrm{F}$ & Angina & 2 Vessel disease \\
3 & $66 / \mathrm{M}$ & Angina & 2 Vessel disease \\
4 & $61 / \mathrm{F}$ & Angina & 2 Vessel disease \\
5 & $63 / \mathrm{M}$ & Angina & Not done \\
6 & $62 / \mathrm{M}$ & Angina & 2 Vessel disease \\
7 & $64 / \mathrm{M}$ & Angina & Single vessel disease \\
8 & $64 / \mathrm{M}$ & Angina & 2 Vessel disease \\
9 & $60 / \mathrm{M}$ & Angina & 3 Vessel disease \\
10 & $41 / \mathrm{F}$ & Angina & 3 Vessel disease \\
11 & $54 / \mathrm{M}$ & Angina & 2 Vessel disease \\
12 & $64 / \mathrm{M}$ & Angina & 2 Vessel disease \\
13 & $55 / \mathrm{M}$ & Angina & Not done \\
\hline
\end{tabular}

$\star$ Coronary artery disease ( $>70 \%$ stenosis of the vessel lumen).

$\geqslant 3 \mathrm{~mm}$ at peak exercise. Patients were entered into the study after informed written consent had been obtained.

\section{DRUG DOSAGE AND ADMINISTRATION}

The study was divided into five two week periods. After a single blind placebo control period, labetalol was given in twice daily doses for the following eight weeks. The labetalol dosage was increased at two weekly intervals. The total daily labetalol dosage for the four treatment periods was $200 \mathrm{mg}, 300 \mathrm{mg}, 400$ $\mathrm{mg}$, and $600 \mathrm{mg}$.

\section{ANTI-ANGINAL ASSESSMENT}

Patients kept diaries to record the frequency of angina attacks and glyceryl trinitrate consumption. At each visit supine and standing blood pressures were measured using a standard sphygmomanometer. Patients were asked if they had experienced any side effects but were not questioned about specific symptoms.

\section{EXERCISE TESTING}

Maximal symptom limited treadmill exercise tests were performed using the Bruce protocol before entry into the study and in the second week of the placebo period and each treatment period. In each of the two week periods exercise tests were performed three hours and 12 hours after dosage on separate days. The treadmill, the recording equipment, and the recording methods have been described previously. ${ }^{10}$

\section{STATISTICAL METHODS}

To assess drug efficacy, the frequency of angina attacks and glyceryl trinitrate consumption in the control period were compared with those during treatment with labetalol. Exercise tolerance during treatment was compared with that with the second placebo to minimise any learning or training effect. Two way analysis of variance ${ }^{11}$ was done to test the null hypothesis. Where differences were detected at at least the $5 \%$ level, the Newman-Keuls test ${ }^{12}$ was used to compare the different treatments. Results are expressed as mean (SEM) unless stated otherwise.

\section{Results}

Full data were obtained in 10 patients. One patient required a reduction in dosage because of mild heart failure. Two patients were withdrawn from the study, one because of "scalp tingling" while taking labetalol and one because of progressive worsening of his angina while taking placebo.

\section{ANGINA ATTACK FREQUENCY}

The frequency of angina attacks decreased in all of the 10 patients who completed the study (Fig. 1). The reduction, compared with the placebo period, was significant with total daily labetalol doses of $300 \mathrm{mg}$, $400 \mathrm{mg}$, and $600 \mathrm{mg}$ ( $<<0.01$ for each of these). With $400 \mathrm{mg}$ daily and $600 \mathrm{mg}$ daily, patients had significantly less angina than with $200 \mathrm{mg}$ daily $(\mathbf{p}<\mathbf{0 . 0 5}$ and $\mathbf{p}<\mathbf{0 . 0 1}$ respectively). With between 300 $\mathrm{mg}$ and $600 \mathrm{mg}$ daily, there was a further minor reduction in the frequency of angina attacks, but this was not statistically significant.

\section{GLYCERYL TRINITRATE CONSUMPTION}

The reduction in nitrate consumption paralleled the reduction in angina attack frequency (Fig. 1). There was a significant reduction in nitrate tablet consumption with labetalol $300 \mathrm{mg}$ daily $(p<0.05)$ and also with $400 \mathrm{mg}$ daily $(\mathrm{p}<0.01)$ and $600 \mathrm{mg}$ daily $(p<0.01)$ compared with placebo. With $400 \mathrm{mg}$ and $600 \mathrm{mg}$ daily, fewer glyceryl trinitrate tablets were taken than with $200 \mathrm{mg}$ daily $(p<0.05)$. The further reduction on increasing the total daily labetalol dose from $300 \mathrm{mg}$ to $600 \mathrm{mg}$ was not significant.

\section{EXERCISE TOLERANCE}

Fig. 2 and Table 2 show exercise tolerance three hours after drug administration (expressed as seconds of the Bruce protocol). Exercise time with placebo was the 


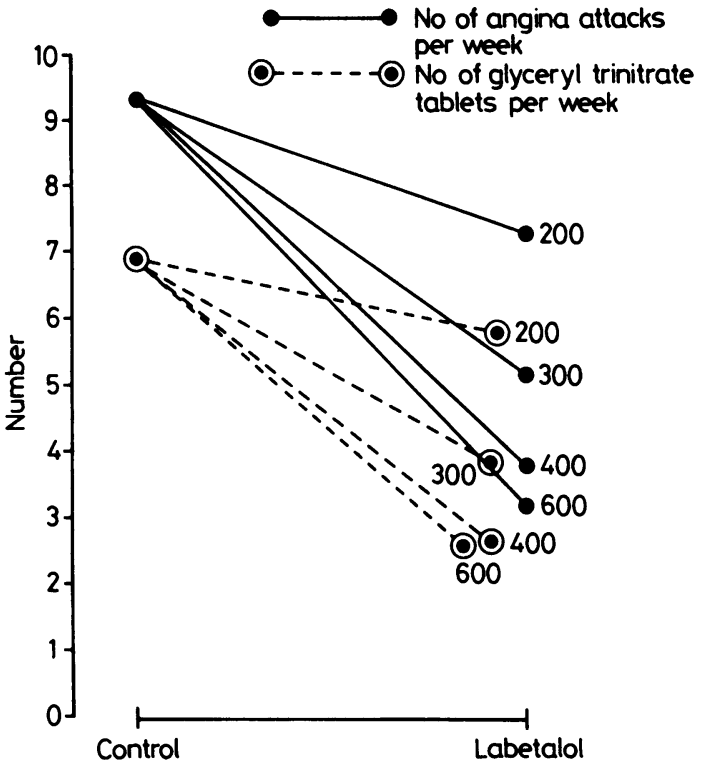

Fig. 1 Relation of frequency of anginal attacks and glyceryl trinitrate consumption to doses of labetalol.

same as that before entry without treatment. With labetalol $200 \mathrm{mg}$ daily, exercise time was not significantly greater than with placebo. With labetalol $300 \mathrm{mg}, 400 \mathrm{mg}$, and $600 \mathrm{mg}$ daily, exercise tolerance was greater than with placebo (in each case $p<0.01$ ), and also greater than with labetalol $200 \mathrm{mg}$ daily $(\mathrm{p}<\mathbf{0 . 0 5}, \mathrm{p}<\mathbf{0 . 0 1}$, and $\mathbf{p}<\mathbf{0 . 0 1}$ respectively). The exercise time with labetalol $600 \mathrm{mg}$ daily $(413(50.6) \mathrm{s})$ was $55 \%$ greater than with placebo but was not significantly greater than with labetalol $300 \mathrm{mg}$ daily. Exercise tolerance three hours after dosage was not significantly different from that 12 hours after dosage.

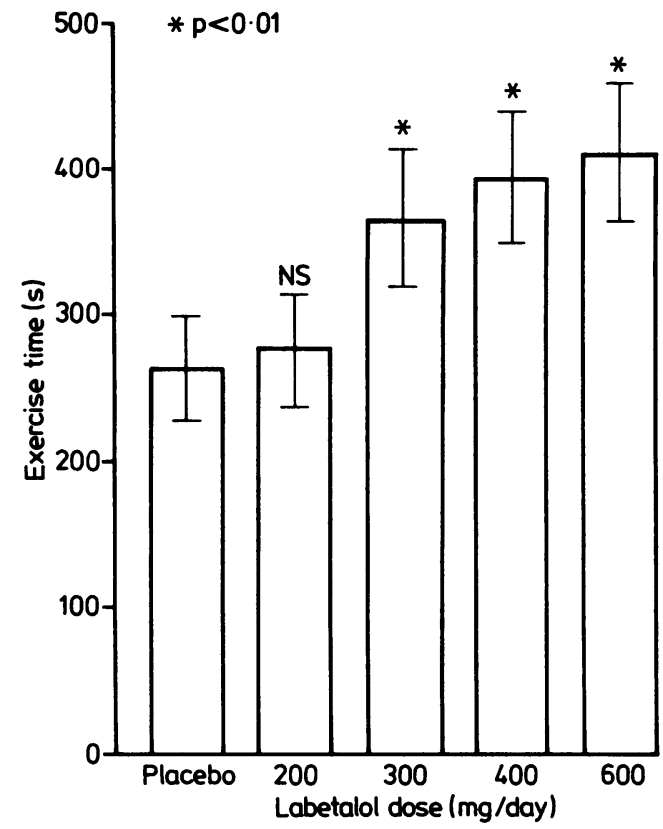

Fig. 2 Relation of exercise tolerance to labetalol dosage. ${ }^{\star} p<0.01$ vs placebo.

\section{BLOOD PRESSURE AND HEART RATE (TABLE 2)}

The resting systolic blood pressure was significantly reduced by labetalol in a total daily dose of $200 \mathrm{mg}$ $(p<0.01)$. With 300 and $400 \mathrm{mg}$ of labetalol daily, the resting systolic blood pressure was significantly lower than with placebo ( $\mathrm{p}<0.01$ at both dosages) but not lower than with $200 \mathrm{mg}$ daily. With labetalol $600 \mathrm{mg}$ daily the resting systolic pressure was significantly lower than with placebo $(p<0.01)$ and also lower than with all the other dosages of labetalol $(p<0.05)$. The

Table 2 Rest and exercise data

\begin{tabular}{|c|c|c|c|c|c|c|c|}
\hline & \multicolumn{3}{|l|}{ Placebo periods } & \multicolumn{4}{|c|}{ Labetalol dose (mg/day) } \\
\hline & Control & $1 s t$ & $2 n d$ & 200 & 300 & 400 & 600 \\
\hline \multicolumn{8}{|c|}{ Exercise data } \\
\hline $\begin{array}{l}\text { Heart rate at peak exercise } \\
\text { (beats/min) }\end{array}$ & $134(8 \cdot 3)$ & $130(7 \cdot 1)$ & $129(7 \cdot 0)$ & $115(4 \cdot 9)$ & $119(6 \cdot 1)$ & $119(4 \cdot 7)$ & $117(5 \cdot 2)$ \\
\hline $\begin{array}{l}\text { Peak exercise rate-presssure } \\
\left.\text { product (mm } \mathrm{Hg} \mathrm{min}^{-1}\right)\end{array}$ & 23078 (2185) & $22769(2.74)$ & 23943 (1712) & $18654(1270)^{\star}$ & $18661(1329)^{\star \star}$ & $17809(869)^{\star \star}$ & $16790(838)^{\star \star}$ \\
\hline $\begin{array}{l}\text { Heart rate at workload } \\
\text { achieved in second } \\
\text { placebo exercise test } \\
\text { (beats/min) }\end{array}$ & & & $129(6 \cdot 9)$ & $113(5 \cdot 0)^{\star \star}$ & $113(5 \cdot 4)^{\star \star}$ & $109(5 \cdot 1)^{\star \star}$ & $110(4 \cdot 2)^{\star \star}$ \\
\hline $\begin{array}{l}\text { Exercise tolerance (seconds } \\
\text { of Bruce protocol) } \\
\text { Maximum ST depression }\end{array}$ & $238(40-2)$ & $251(36 \cdot 6)$ & $266(43 \cdot 9)$ & $306(43 \cdot 8)$ & $369(49 \cdot 3)^{\star \star}$ & $396(47 \cdot 7)^{\star \star}$ & $413(50.6)^{\star \star}$ \\
\hline $\begin{array}{l}\text { Maximum ST depression } \\
\text { at peak exercise }(\mathrm{mm})\end{array}$ & & & $2.0(0.3)$ & $1.6(0.2)$ & $1.6(0.4)$ & $1.8(0.2)$ & $1.7(0.2)$ \\
\hline $\begin{array}{l}\text { Heart rate (beats } / \mathrm{min}) \\
\text { Blood pressure }(\mathrm{mm} \mathrm{Hg})\end{array}$ & $77(2 \cdot 4)$ & $73(2 \cdot 6)$ & $75(2.8)$ & $69(3.6)$ & $68(2 \cdot 5)$ & $66(1 \cdot 5)^{\star}$ & $71(2 \cdot 1)$ \\
\hline $\begin{array}{l}\text { Systolic } \\
\text { Diastolic }\end{array}$ & $\begin{array}{r}154(7 \cdot 1) \\
91(2 \cdot 6)\end{array}$ & $\begin{array}{r}153(7.6) \\
87(3.6)\end{array}$ & $\begin{array}{r}152(7.4) \\
86(2.9)\end{array}$ & $\begin{array}{l}139(7 \cdot 3)^{\star \star} \\
80(4 \cdot 2)^{\star}\end{array}$ & $\begin{array}{c}131(6 \cdot 2)^{\star \star} \\
79(2 \cdot 7)^{\star}\end{array}$ & $\begin{array}{r}133\left(6 \cdot 7^{\star \star}\right. \\
76(3 \cdot 5)^{\star \star}\end{array}$ & $\begin{aligned} & 121(6 \cdot 1)^{\star \star} \\
& 75(2 \cdot 4)^{\star \star}\end{aligned}$ \\
\hline
\end{tabular}

${ }^{\star} \mathrm{p}<0.05 ;{ }^{\star \star} \mathrm{p}<0.01$ (significance of difference from placebo). 
resting diastolic blood pressure was significantly lower with labetalol than with placebo, but there was not a significant difference in resting diastolic pressure between the different labetalol dosages.

There was a trend towards a reduction in resting heart rate which became significant at the $5 \%$ level with labetalol $400 \mathrm{mg}$ daily. With $600 \mathrm{mg}$ daily the resting heart rate was not significantly different from that with placebo.

The heart rate at peak exercise with labetalol was not significantly different from that with placebo. With labetalol, however, significantly higher workloads were achieved: When the heart rate at peak exercise with placebo was compared with that at the same workload with labetalol, a significant reduction was seen at all dosages $(p<0.01$ at each labetalol dosage).

The rate-pressure product at peak exercise was significantly reduced with all of the labetalol dosages (Table 2). The degree of reduction with $600 \mathrm{mg}$ daily was not significantly different from that with $200 \mathrm{mg}$ daily.

\section{DEGREE OF ST SEGMENT CHANGE}

Table 2 shows the maximum ST segment change seen on the 12 lead electrocardiogram at peak exercise at each dosage. There was a trend towards a reduction in the degree of ST segment depression, but this did not reach statistical significance.

\section{EFFECT OF POSTURE ON SYSTOLIC BLOOD PRESSURE}

Three hours after dosage with the highest labetalol dose there was a postural fall in systolic blood pressure in seven out of the 10 patients. The greatest fall was from 125 to $105 \mathrm{~mm} \mathrm{Hg}$. In the others the fall in systolic blood pressure ranged from 5 to $10 \mathrm{~mm} \mathrm{Hg}$. None of the patients had symptoms referable to postural hypotension.

\section{SIDE EFFECTS AND WITHDRAWALS}

One patient (case 3) was withdrawn after three days of treatment because of scalp tingling. One patient (case 6) developed dyspnoea on exertion while taking labetalol $200 \mathrm{mg}$ daily. He did not have clinical signs of heart failure, but chest $x$ ray films showed pulmonary venous congestion which was not previously present. Dosage reduction to $100 \mathrm{mg}$ daily and the addition of a thiazide diuretic resulted in a pronounced symptomatic improvement. With placebo treatment he had experienced 14 attacks of angina a week and had consumed four glyceryl trinitrate tablets a week. With his final labetalol dosage he experienced only one attack of angina in a six week period. His exercise tolerance increased from $160 \mathrm{~s}$ in the control period to $221 \mathrm{~s}$ with his final dosage regimen, and his symptomatic improvement was maintained over a six month follow up period.

One patient (case 8) experienced progressive worsening of his angina while taking placebo and was withdrawn from the study before receiving labetalol. No patients complained of fatigue or cold extremities and none had symptoms referrable to postural hypotension.

\section{Discussion}

Labetalol is an agent with combined alpha and beta adrenoceptor antagonist properties. ${ }^{4}$ It has a competitive antagonist action at both alpha and beta receptors, ${ }^{4}$ and its beta blocking action is non-selective. ${ }^{4}$ The intravenous administration of labetalol results in a fall in blood pressure and has a variable but generally minor effect on heart rate. 4578 Peripheral vascular resistance has been shown to fall after its administration, ${ }^{57}$ as has coronary vascular resistance. ${ }^{5}$ Because of its haemodynamic effects its main role has been in the management of hypertension. In this context it has been shown to be effective, when given orally or intravenously, ${ }^{6-8}$ and safe, even in the setting of acute myocardial infarction. ${ }^{8}$

The value of beta blockade in the management of angina pectoris is well established. ${ }^{2}$ Pure beta blockade results in a reduction in resting heart rate and blood pressure and a blunting of the heart rate and blood pressure responses to exercise. ${ }^{2}$ These actions result in a decreased myocardial oxygen requirement and are of benefit to the angina sufferer. ${ }^{13}$ The benefits of beta blockade are, however, achieved at the expense of a decrease in cardiac output and a variable increase in peripheral vascular resistance ${ }^{314}$; these actions may be of importance in the production of the not infrequent side effects of fatigue and cold extremities.

Pure alpha blockade may be disadvantageous to patients with angina. Administration of the alpha receptor antagonist phentolamine results in a fall in peripheral vascular resistance and a fall in blood pressure $^{15}$ but any potential benefit, in terms of reduced myocardial oxygen requirement, is offset by the accompanying reflex tachycardia. ${ }^{1516}$ In some patients phentolamine may actually precipitate angina attacks. ${ }^{15}$ Selective alpha ${ }_{1}$ receptor blockade with prazosin has less tendency to produce reflex tachycardia, but exacerbation of anginal symptoms has also been described with the use of this agent. ${ }^{16}$

Alpha blockade alone clearly has disadvantages. There is some evidence, however, that the combination of alpha and beta blockade may be more effective than beta blockade alone in the treatment of angina. ${ }^{17}$ In comparison with beta blockade alone the combination may provide additional benefit in terms of patient 
tolerance, since there is less depression of left ventricular function and less effect on peripheral vascular resistance than beta blockade. ${ }^{3}$

Labetalol is the only agent currently available that has combined alpha and beta adrenoceptor antagonist properties. It has been shown to ameliorate anginal symptoms in hypertensive patients with angina, but its effects in normotensive patients have not been previously evaluated in a controlled way. In this study, all the patients who received labetalol experienced an improvement in their anginal symptoms and an increase in their exercise capacity. These beneficial effects were statistically significant with the labetalol dose of $150 \mathrm{mg}$ given twice daily. There was a trend towards further improvement with the administration of $200 \mathrm{mg}$ and $300 \mathrm{mg}$ twice daily, but compared with $150 \mathrm{mg}$ twice daily this was not significant.

Labetalol caused a reduction in resting blood pressure and a minor reduction in resting heart rate. The latter effect was less than would be expected with agents such as propranolol or atenolol ${ }^{12}$ and probably reflects the balance between the depressant effect of beta blockade on the sinus node and the tendency to reflex tachycardia in response to the alpha blockade mediated vasodilatation. The depression of resting heart rate was significant with $200 \mathrm{mg}$ of labetalol twice daily but not with $300 \mathrm{mg}$ twice daily. This probably reflects a response to the greater blood pressure lowering effect of the higher dosage.

Labetalol treatment was generally well tolerated; only one patient had to be withdrawn from the study in the active treatment period. This patient had the uncommon but well documented side effect of scalp tingling. ${ }^{18}$ In view of labetalol's alpha blocking action, evidence of postural hypotension was sought; the greatest postural fall in systolic pressure was 20 $\mathrm{mm} \mathrm{Hg}$. No patient had symptoms that could be attributed to postural hypertension, and for the group as a whole the lying and standing systolic pressures were not significantly different.

In conclusion, labetalol is an effective antianginal agent that is well tolerated by normotensive patients and can be given in twice daily doses. Significant benefit was observed at a dose of $150 \mathrm{mg}$ twice daily, and only minor improvement was achieved by further increases in dosage. One patient developed mild heart failure with the lowest dose, and it would seem prudent therefore to start treatment with $100 \mathrm{mg}$ of labetalol twice daily and to titrate the dosage to suit the individual patient's needs. Labetalol has promise in the treatment of angina, as it may have advantages over beta blockade alone and merits further study.

We thank Glaxo Pharmaceuticals for financial support.

\section{References}

1 Hamer J, Sowton E. Effects of propanolol on exercise tolerance in angina pectoris. Am $\mathcal{F}$ Cardiol 1966; 18: 354-60.

2 Jackson G, Harry JD, Robinson C, Kitson D, Jewitt DE. Comparison of atenolol with propranolol in the treatment of angina pectoris with special reference to once daily administration of atenolol. Br Heart $\mathcal{f}$ 1978; 40: 998-1004.

3 Silke B, Nelson GIC, Ahuja RC, Taylor SH. Comparative haemodynamic dose response effects of propranolol and labetalol in coronary heart disease. Br Heart $\mathcal{F}$ 1982; 48: 364-71.

4 Richards DA, Prichard BNC, Boakes AJ, Tuckman J, Knight EJ. Pharmacological basis for antihypertensive effects of intravenous labetalol. Br Heart f 1977; 39: 99 106.

5 Gagnon RM, Morissette M, Présant S, Savard D, Lemire $\mathrm{J}$. Hemodynamic and coronary effects of intravenous labetalol in coronary artery disease. Am f Cardiol 1982; 49: 1267-9.

6 Frick MH, Pörsti P. Combined alpha and beta adrenoceptor blockade with labetalol in hypertension. $\mathrm{Br}$ Med F 1976; i: 1046-8.

7 Joekes AM, Thompson FD. Acute haemodynamic effects of labetalol and its subsequent use as an oral hypotensive agent. $\mathrm{Br} \mathcal{F}$ Clin Pharmacol 1976; 3 (suppl 3): 789-93.

8 Timmis AD, Fowler MB, Jaggarao NSV, Chamberlain DA. Labetalol infusion for the treatment of hypertension in acute myocardial infarction. Eur Heart $\mathcal{F} 1980 ; 1$ : 413-6.

9 Halprin S, Frishman W, Kirschner M, Strom J. Clinical pharmacology of the new beta adrenergic blocking drugs. Part II. Effects of oral labetalol in patients with both angina pectoris and hypertension: a preliminary experience. Am Heart f 1980; 99: 388-96.

10 Akhras F, Upward J, Stott R, Jackson G. Early exercise testing and coronary angiography after uncomplicated myocardial infarction. Br Med f 1982; 284: 1293-4.

11 Ryan CT. "Minitab" student handbook. Boston: Doxbury Press, 1981.

12 Armitage P. Statistical methods in medical research. Oxford, London, Edinburgh, Melbourne: Blackwell Scientific Publications, 1971: 202-7.

13 Robinson BF. Relation of heart rate and systolic blood pressure to the onset of pain in angina pectoris. Circulation 1967; 35: 1073-83.

14 Robinson C, Jackson G, Fisk C, Jewitt D. Haemodynamic effects of atenolol in patients with coronary artery disease. Br Heart $\mathcal{f} 1978 ; 40: 22-8$.

15 Taylor SH, Sutherland GR, Mackenzie GJ, Staunton HP, Donald KW. The circulatory effects of intravenous phentolamine in man. Circulation 1965; 31: 741-54.

16 Charness ME, Fishman JA, Robertson D. Exacerbation of angina pectoris by prazosin. South Med F 1979; 72: $1213-4$.

17 Collins P, Sheridan DJ. Alpha adrenoceptor blockade improves exercise tolerance in angina pectoris. $\mathrm{Clin} \mathrm{Sci}$ 1984; 66: 40P.

18 Hua ASP, Thomas GW, Kincaid-Smith P. Scalp tingling in patients on labetalol [Letter]. Lancet 1977; ii: 295. 